\title{
Application analysis of the recovery fresh air heat pump units in the public building in the cold and serious cold regions
}

\author{
Chen Aoxue,Ran Chunyu \\ School of Municipal \& Environmental Engineering \\ Jilin Institute of Architectural and Civil Engineer \\ Changchun, P.R.China \\ chenaoxue2002@163.com
}

\author{
Liu Hailong \\ Fourth Design Institute \\ Jilin Provincial Architectural Design Institute Co.,Ltd \\ Changchun, P.R.China \\ liuhailong2002@163.com
}

\begin{abstract}
This article analysis the running conditions and existing problems of air conditioning system for existing public buildings in the cold and serious cold regions in winter,and compares analysis of the solution of the anti freezing measures for the fresh air unit,introduces the recovery exhaust energy by the means of heat exchange to resolve the existing problems of air conditioning system in winter.The results show that the outdoor temperature changes from $-25 \sim 10^{\circ} \mathrm{C}$ degree, the degree of air supply can reach more than 10 degree, which means that system which recovers the exhaust energy can preheat the fresh air more than 10 degree.The COP of recovery fresh air heat pump units reaches more than 3.8 , and the heat recovery efficiency up to 82\%.It can prolong the heat pump units and the fresh air units run in the period of heating, guarantee well IAQ for a long time.
\end{abstract}

Index Terms - the cold and serious cold regions, the recovery fresh air heat pump units, anti freezing, heat recovery efficiency, COP.

\section{INTRODUCTION}

With the growth of economy and technology, the air source heat pump is more and more frequently used in the public buildings. The air-source heat pump is a convenience and with higher energy efficiency rating; it can make the best of low temperature energy sources of the atmosphere circumstance, and has less pollution to the region. The air source heat pump has energy conservation and environment protection effects; it is a kind of green air conditioning technique.But in northern, northwestern and northeastern of China,the air source heat pump can not work in the period of heating. When running in winter in the cold and serious cold regions, the fresh air units are often harmed by frostbite; it brings on the decline of Indoor Air Quality.Provided use the outdoor air as the low temperature heat source of air source heat pump,heat pump units can not available in the whole heating period,heating capacity substantially reduced,energy efficiency coefficient (COP) fell sharply,the outdoor heat exchanger became frosting, and it can't run.At the same time, in terms of balancing ventilation requirements, there had a large number of exhaust heating in the public buildings, which were discharged directly, it caused the waste of energy.In order to solve the above problems, we combinate the air source heat pump and fresh air system and exhaust system, recovery the exhaust heating of the public buildings to heating fresh air, when the outdoor air temperature is lower than a set value in winter, we start the heating pump to heating the fresh air, this method can increase the operation time of the heat pump unit and fresh air unit in the heating period effectively, it also can solve the running problem of the heat pump units and fresh air units in cold and serious cold regions, it can ensure good indoor air quality for a long time.

\section{THE RUNNING CONDITIONS AND EXISTING PROBLEMS OF AIR SOURCE HEAT PUMP IN THE EXISTING PUBLIC BUILDINGS}

\section{A. Limitations of air source heat pump application in the cold and serious cold regions}

Although there are many advantages in the air source heat pump, it suffers from outdoor environmental restrictions enormously, and it has limitations of the application in the cold regions, this is the main reason why the air source heat pump is widely used only in the south of the Yellow River regions in China, but if the air source heat pump system does not make any improvements, it will not work in winter in the north areas of the Yellow River.The heating capacity decreased rapidly with the outdoor temperature falls, but the heating requirements rises quickly with the outdoor temperature declines, when the outside temperature is very low, the heating capacity will be too small to satisfy the heating demand in these areas in winter.At the same time, with the reduction of the outdoor environment temperature, the COP of the unit has decreased substantially, the compression ratio of the compressor will be more and more higher, it leads to exhaust temperature rising, and it will seriously damage the compressor if the system runs for a long time [1].In addition,from the running effect of air source heat pump, the accuracy of the heat pump defrost is not very desirable, it main shows that the existing defrosting criterion can not adapt to the wide range operating conditions in the north, the heat pump defrosting by mistake is serious, the time of defrosting is too long so that it often leads the indoor temperature fluctuation obviously, there has a feeling of cold wind clearly. It is difficulty to start units in low temperature working conditions, the units are often prone to burn machine in the startup phase or at the end of the defrosting when the restore heating [2] . 


\section{B. Limitations of fresh air units application in the cold and serious cold regions}

In winter, air conditioning systems rarely supply fresh air in cold and serious cold regions of China.Fresh air units often frost crack, it tends to occur on the heating coil(usually copper tube), when the water temperature in the heating coil of the unit is less than the freezing point temperature which corresponding to the working pressure, the water comes to freezing, and its volume expands, it resulted in the burst of heater tubes eventually.It cause water leakage, unit is damaged, causing serious economic losses.Fresh air units can not run normally, it causes the declination of indoor air quality, and make people who life and work for a long time in modern air conditioning buildings show more and more heavy pathological reactions, such as "sick building syndrome". According to the survey,the traditional method of fresh air unit antifreeze, such as "the method of controlling backwater temperature", "the method of controlling the temperature of tube wall", "electric heating mode" and "mix water way",can not successfully solve the problem of fresh air unit freezing [3].

\section{THE METHOD OF FRESH AIR UNIT ANTI-FREEZING AND ITS EXISTING PROBLEMS IN PUBLIC BUILDINGS}

In the cold and serious cold regions, air conditioning system often uses electric heating method [4] to solve the frosty problem of fresh air unit in public buildings in winter, this method is used for intermittent operation fresh air system. In order to reduce the loss of heat and cold air infiltration when the system stops running, electric thermal insulation is installed at air inlet valve, and setted electric heater between heat preservation butterfly valve and electric leafy regulator valve, you should just make the temperature between electric thermal insulation valve and leafy valve is higher than $5{ }^{\circ} \mathrm{C}$, it can avoid the problem of freezing cold air heater. But this method requires a certain operation cost and increases initial investment,owing to the increase in control links, the quantity of operation management is improved. It needs a large of running energy consumption, it leads to large electric capacity and the high cost of operation and management.

There is another way to prevent the frosty of air units, it is on duty fan[4], this method is also used for intermittent operation fresh air system. According to calculate air rate,it sets a wind pipe which can require air between butterfly valve and electric leafy regulator, it leads the wind from corridor,it controls air conditioning system in terms of on duty fan and electric butterfly valve, at the same time,it controls system with electric thermal insulation valve and electric leafy regulator.When it stops running, electric thermal insulation valve and electric leafy valve close, open the electric butterfly valve, the on duty fan starts running, extract air supply into air duck between electric thermal insulation valve and electric porous regulator valve, keeping the temperature above $5{ }^{\circ} \mathrm{C}$, which can prevent the air unit heating coil freezing.

But for hospitals, hotels, shopping malls and other large public buildings, in order to guarantee the good indoor air quality in winter, the fresh air units must make the system running continuously. If use electric heating method or on duty fan to ensure the normal operation of the unit in serious cold regions in winter, it has a huge power consumption and high operating costs, and it is also the reason why fresh air unit often shut down in serious cold region in winter,resulting in air conditioning system became hot air heating system in winter, and lost the significance of indoor air quality.

\section{APPLICATION OF THE RECOVERY FRESH AIR HEAT PUMP UNITS IN THE PUBLIC BUILDING IN THE COLD AND SERIOUS COLD REGIONS}

Recovery fresh air heat pump units are the evaporator (condenser) of the heat pump units instead of the air heater (cooler), which the heating (cooler) medium is water in fresh air conditioning unit. The composition of the heat pump heat recovery system with exhaust energy is simple, it is made up of compressor, the throttle body, two sets of air/refrigerants heat coil which are placed in the exhaust system and fresh air system, and directional control valve. In the summer working condition, the side of the exhaust pipe is plate condenser, which is cooling the air (it is extracted heating from the fresh air), making the full use of the cold energy from the exhaust air, and reducing the load of heat pump unit. In the winter conditions, directional control valve changes the flow of refrigerant, the side of exhaust coil is evaporator, the side of the fresh air coil is condenser; the system acquires the heat from the side of exhaust air (cooling the exhaust), and recycling the exhaust energy,heating the fresh air, because of refrigerant freezing point lower than the possible temperature in north cold area, working above the temperature of freezing point,it can avoid freezing heater,the system reduces the load of heat pump unit and enhancing the using efficiency and running time of heat pump units in cold and serious cold regions [5][6].

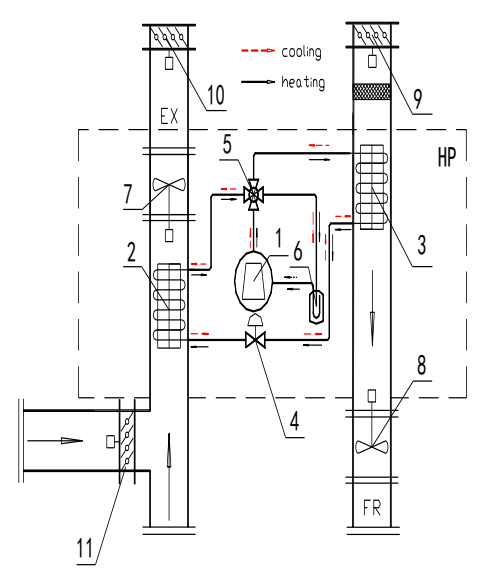

Fig. 1. .Principle of the recovery fresh air heat pump units in cold and serious cold regions

1Compressor;2Evaporator;3Condenser;4Throttle;5Cross valve;6Separator;7Exhaust fan;8Supply fan;9 10 11Electro motion insulating calve. 
When the outdoor air temperature is lower than a set value in winter, we start the heating pump to heating the fresh air, it can ensure that antifreeze requirements of the air heater coil unit in winter,solve the problem of frost, condensation and false defrosting of air source heat pump system.The experimental figure of recovery fresh air heat pump units is shown in figure 1 .The refrigerant flow diagram of the recovery fresh air heat pump units is shown in figure 2 .

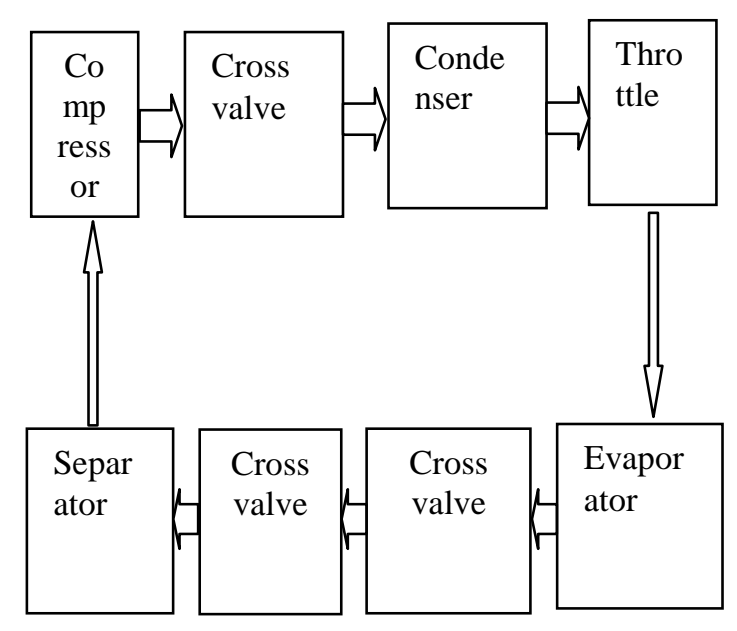

Fig . 2. The refrigerant flow diagram of the recovery fresh air heat pump units

\section{EXPERIMENTAL STUDY ON RECOVERY FRESH AIR HEAT PUMP UNIT}

In order to study and development of the recovery fresh air heat pump units reliably, the experimental object is a small room, the condition of laboratory which temperature and humidity is good. The main tested following parameter: Indoor temperature, outdoor temperature, supply air temperature, exhaust air temperature and the heat pump power consumption.

During the operation stage, the supply air temperature and indoor temperature is stable and the fluctuation is small. The outdoor temperature changes from $-25 \sim 10^{\circ} \mathrm{C}$ degree, the temperature change curves is shown in figure 3.Heating capacity and COP change curves is shown in figure 4.Heating recovery efficiency of recovery fresh air heat pump units is shown in figure 5. Electricity consume compare of the unit and electricity heater is shown in figure 6. When the supply air temperature and indoor temperature is stable and the fluctuation is small. The outdoor temperature changes from $25 \sim 10^{\circ} \mathrm{C}$ degree, which means that system which recovers the exhaust energy can preheat the fresh air more than 10 degree. The coefficient of performance (COP) of recovery fresh air heat pump units reaches more than 3.8 . The recovery efficiency of recovery fresh air heat pump units achieve up to $82 \%$, the recovery capacity is considerable. Compare with fresh air heating with electric heater, fresh air heating with recovery fresh air heat pump units can save running costs about $27 \%$.

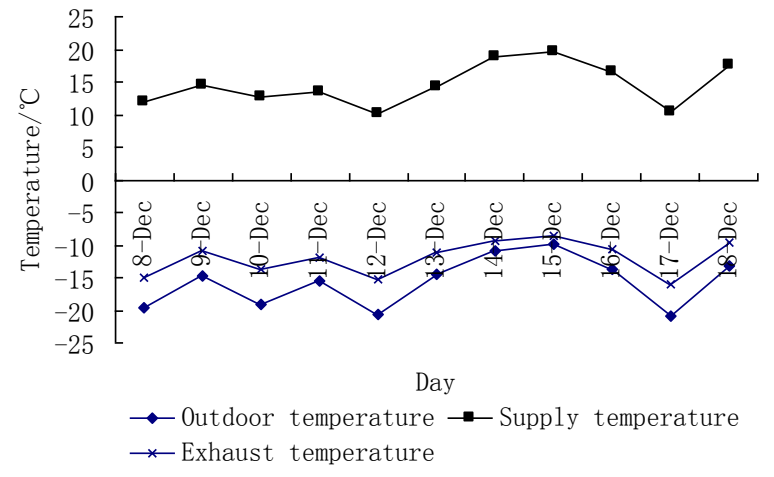

Fig.3. Principle of the recovery fresh air heat pump units in cold and serious cold regions

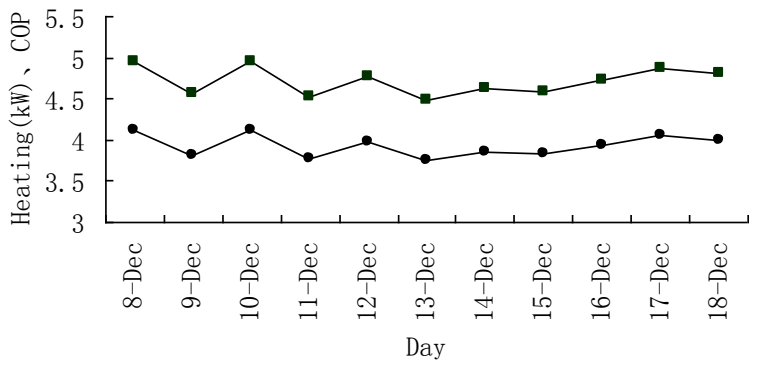

- The capacity of recovery fresh air heat pump units

$\rightarrow$ The COP of recovery fresh air heat pump units

Fig. 4. COP and heating capacity change in testing period

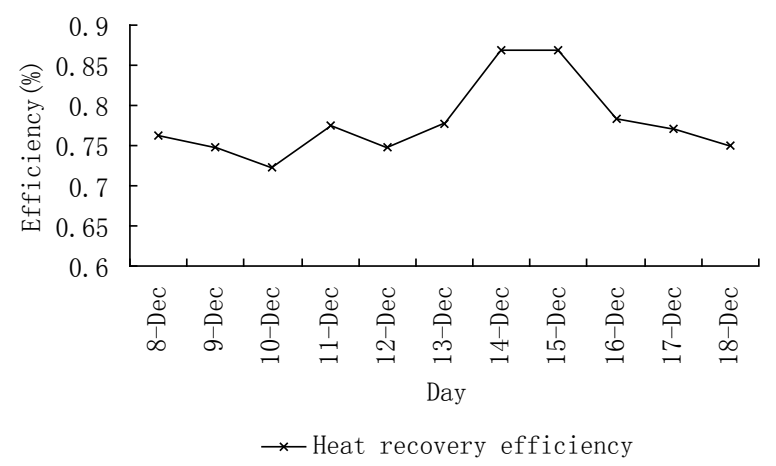

Fig. 5. Heating recovery efficiency of recovery fresh air heat pump units in testing period 


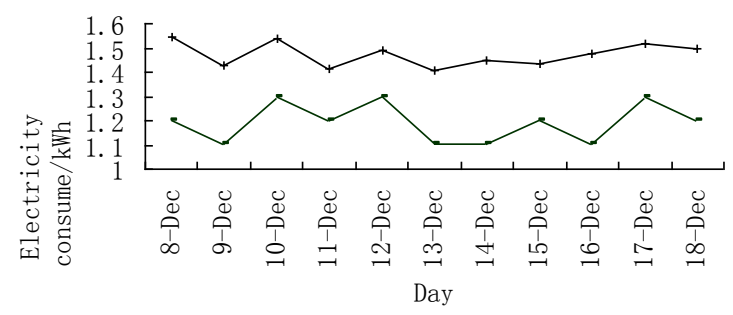

$\longrightarrow$ Electricity consume of electricity heater

- Electricity consume of recovery fresh air heat pump units

Fig. 6. Electricity consume compare of the unit and electricity heater

\section{CONCLUSION}

With carrying on the measured study to the recovery fresh air heat pump units, the system operation characteristics and the actual operating results have been primarily mastered. By analyzing the operation results of the system:

During the operation stage, the supply air temperature and indoor temperature is stable and the fluctuation is small. The outdoor temperature changes from $-25 \sim 10^{\circ} \mathrm{C}$ degree, which means that system which recovers the exhaust energy can preheat the fresh air more than 10 degree. The COP of recovery fresh air heat pump units reaches more than 3.8, completely meet the requirements of the national standards. The recovery efficiency of recovery fresh air heat pump units achieve up to $82 \%$, the recovery capacity is considerable. Compare with fresh air heating with electric heater, fresh air heating with recovery fresh air heat pump units can save running costs about $27 \%$.

Analyzing the operation results of the system, recovery fresh air heat pump units can effectively solve the problem which fresh air units can not work well in cold and serious regions,it makes use of the exhaust fully,mix the exhaust and outdoor air,and raise the intake air temperature of heat exchanger,thereby,prolong the heat pump units and the fresh air units run in the period of heating,IAQ is well guaranteed for a long time.

\section{ACKNOWLEDGMENT}

The project has been supported by the science and technology development project funding for youth of Jilin Architectural and Civil Engineer Institute, project Numbers: NO. J20111031, thanks to technology and financial support of Jilin Architectural and Civil Engineer Institute.

\section{REFERENCES}

[1] Xinhu Chai, Guoyuan Ma, "State of knowledge and current challenges in the ASHP developed for the cold areas" Proceedings of the energy and environment [J], vol.5, 2002.

[2] Guoyuan Ma, Shuangquan Shao, "Research on heat pump cycle for air conditioning in cold regions" , Proceedings of the Acta Energiae Solaris Sinica[J], vol.1,2002.

[3] Chunqing WANG, Chunyu RAN, Lan ZHANG. Analysis of Using Air-source Heat Pump With Exhaust Heat Recovery in The Cold Regions. Proceedings of The 6TH International Symposium on Architectural Interchanges in Asia[J]. Daegu, Korea. 2006, October, 25-28:857-862.

[4] Chunyu RAN, Chunqing WANG, Fenghua GE, Lan ZHANG. Research on The Air-source Heat Pump Application in Cold and Sever Regions. Proceedings of Clima 2007 WellBeing Indoors[J]. Helsinki, Finland. 2007, June, 1014 : 223-229.

[5] Rongyi ZHAO, Cunyang FAN, Dianhua XUE, “Air conditioning” , Proceedings of the China Architecture Building Press[M],pp. 25-26, 1994.

[6] Yajun LU, Zuiliang MA,Huaping ZOU, "Heating ventilation and Air conditioning" , Proceedings of the China Architecture Building Press[M], Beijing, vol.3, pp. 345-350, 2002. 